\title{
Refractory period following bronchoconstriction provoked by histamine in asthmatic subjects
}

\author{
M J CONNOLLY, S C STENTON, A J AVERY, E H WALTERS, D J HENDRICK \\ From Newcastle General Hospital and the University of Newcastle upon Tyne
}

\begin{abstract}
To determine whether refractoriness to histamine induced bronchoconstriction occurs, 20 asthmatic subjects aged 19-50 years were tested. Subjects underwent two histamine challenge tests ( 1 and 2) on the same day, the second one being given 45-60 minutes after the first, once the $F E V_{1}$ after test 1 had returned spontaneously to within $90 \%$ of baseline. A further "control" histamine challenge test was carried out on a different day at the same time ( \pm 2 hours) as test 1 . Bronchial responsiveness was recorded as the cumulative dose $(\mu \mathrm{g})$ of histamine provoking a $20 \%$ fall in $\mathrm{FEV}_{1}\left(\mathrm{PD}_{20}\right)$, and the ratio $\mathrm{PD}_{20}$ test $2: \mathrm{PD}_{20}$ test 1 was used to assess refractoriness. The median value of this ratio $(2 \cdot 20)$ was significantly greater than $1(\mathrm{p}=0.003)$, indicating refractoriness at the time of test 2 . By contrast the median ratio $\mathrm{PD}_{20}$ control: $\mathrm{PD}_{20}$ test 1 of 1.03 was not significantly different from 1 . Refractoriness could not be accounted for by failure to regain the initial baseline $F E V_{1}$, though such failure may have exaggerated the effect. An increase in $\mathrm{PD}_{20}$ with the second test was observed uniformly in subjects with moderate or high initial $\mathbf{P D}_{20}$ values but not in those with low values. This suggests that there may be a $\mathrm{PD}_{20}$ threshold of the order 25-100 $\mu \mathrm{g}$ for refractoriness to occur. Refractoriness could exert an important confounding effect in investigations in which repeated histamine tests are carried out at short intervals.
\end{abstract}

\section{Introduction}

Controlled provocation of bronchoconstriction by chemical and physical stimuli is widely used in the investigation of asthma. Immediate refractoriness to further bronchoconstriction has been shown to occur when the initial constrictive episode is provoked by stimuli such as exercise'; hyperventilation ${ }^{2}$; or the inhalation of ultrasonically nebulised distilled water, ${ }^{3}$ leukotriene D4, ${ }^{4}$ and platelet activating factor. ${ }^{5}$ With methacholine the long duration of action makes the investigation of refractoriness difficult. Refractoriness after methacholine provoked bronchoconstriction has, nevertheless, been reported by some investigators though not others. ${ }^{67}$

Histamine has been the subject of more detailed study, though data are still limited and conflicting. In 1980 Schoeffel et al found progressively smaller mean decrements in peak expiratory flow $(38 \%, 34 \%$, and $29 \%$ ) in 16 asthmatic subjects after inhalation of identical doses of histamine at $\mathbf{4 0}$ minute intervals. ${ }^{8}$ This initial hint of refractoriness after histamine

Address for reprint requests: Dr D J Hendrick, Newcastle General Hospital, Newcastle upon Tyne NE4 6BE.

Accepted 27 November 1988 challenge tests has been supported by recent reportsthose of Manning and colleagues, ${ }^{910}$ who retested 11 and eight subjects respectively after 60 minutes using the continuous (Wright) nebulisation method, and of Magnussen and colleagues, who retested nine subjects after 60 minutes using airway resistance to measure bronchial responsiveness. ${ }^{6}$ Controversy has arisen, however, because other studies, using a similar range of methods, have failed to show significant decreases in bronchial responsiveness with closely repeated histamine tests. ${ }^{11-14} \mathrm{We}$ present the results of a study in 20 adults with asthma.

\section{Methods}

\section{SUBJECTS}

Twenty subjects ( 9 male, 11 female) with symptomatic asthma and reversible airway obstruction were recruited from our clinic and student populations. They were not told the purpose of the study. The age range was 19-50 (median 25) years. All were non-smokers and 18 were atopic. Each subject was required to have a forced expiratory volume in one second $\left(\mathrm{FEV}_{1}\right)$ on entry of at least $60 \%$ of the predicted value. Subjects who had had a respiratory tract infection or had received antihistamines, 
cromoglycate, nedocromil, or oral corticosteroids within the preceding six weeks were excluded. They had to avoid oral bronchodilators and aspirin for 48 hours before each histamine test, and inhaled bronchodilators, ipratropium, and corticosteroids for 24 hours.

\section{MEASUREMENT OF VENTILATORY FUNCTION}

FEV $_{1}$ was measured as the mean of three technically satisfactory measurements with a bellows spirometer (Vitalograph Ltd, Buckingham). Baseline FEV , was taken as the mean of three measurements 10 and five minutes before and at the start of the histamine aerosol challenge (that is, the mean of nine recordings).

\section{HISTAMINE SOLUTIONS}

Sequential doubling dilutions of histamine over the range $32-0.03125 \mathrm{mg} / \mathrm{ml}$ were made up daily from a stock solution containing $64 \mathrm{mg} / \mathrm{ml}$ of histamine acid phosphate. The first dilution, to $32 \mathrm{mg} / \mathrm{ml}$, was made with a solution of $0.275 \%$ sodium bicarbonate. All further dilutions were made with a diluent of $0.275 \%$ sodium bicarbonate and $0.8 \%$ sodium chloride. The stock solution and both diluents contained $0.4 \%$ phenol as a preservative. ${ }^{15}$

\section{HISTAMINE CHALLENGE TESTS}

All tests were performed during the afternoon to minimise any effect of circadian rhythms on ventilatory function or bronchial responsiveness. They used a dosimeter technique, ${ }^{16}$ each incremental challenge dose comprising five nebulisations $(50 \mu \mathrm{l})$. Doubling cumulative doses of histamine were administered, beginning with a dose of $1.5625 \mu \mathrm{g}(50 \mu \mathrm{l}$ of histamine solution, $0.03125 \mathrm{mg} / \mathrm{ml}){ }^{17} \mathrm{FEV}_{\text {, was }}$ measured five minutes later and the next histamine dose followed. The challenge sequence was terminated when $\mathrm{FEV}_{1}$ had fallen by $20 \%$ or more or when the maximum cumulative dose $(3.2 \mathrm{mg})$ had been given. No bronchodilator was given at this point.

FEV , was remeasured 45 minutes after the completion of test 1 . If it had returned to $90 \%$ or more of its baseline value, a second baseline was established as the mean $F E V_{1}$ from three further sets of measurements at five minute intervals. Test 2 was then carried out in an identical manner to test 1 . If $\mathrm{FEV}_{1}$ had not returned to $90 \%$ of baseline, further measurements were taken at five minute intervals and the second histamine test was delayed until this level had been attained.

A "control" test was performed on a separate day at the same time ( \pm 2 hours) as test 1 , the two tests being separated by $1-21$ days.

\section{EXPRESSION OF BRONCHIAL RESPONSIVENESS}

The FEV (ordinate, arithmetic scale) following the inhalation of histamine was plotted against histamine dose (abscissa, logarithmic scale). Bronchial responsiveness, expressed as the cumulative dose of histamine $(\mu \mathrm{g})$ causing a $20 \%$ decrement in $\mathrm{FEV}_{1}$ $\left(\mathrm{PD}_{20}\right)$, was calculated from the graph by linear interpolation between the last two values. ${ }^{18}$

\section{STA TISTICAL ANALYSIS}

For statistical analysis we used the computer program Minitab. Baseline FEV, values were compared by Student's $t$ test. A "refractory index" for paired tests was defined by the ratio $\mathrm{PD}_{20}$ test $2: \mathrm{PD}_{20}$ test 1 , a ratio of 1 indicating no refractoriness. As the distribution of the logarithms of these ratios was skewed, the sign test was used to assess whether the median refractory index differed significantly from 1 . The confidence intervals for the median refractory index were calculated from the binomial distribution ( $p=1 / 2 ; n=19$ or 20 ). As exact $95 \%$ confidence intervals could not be derived from the data, we give the intervals with the lowest level of confidence $\geqslant 95 \%$. $^{19}$

\section{Results}

After test $1 \mathrm{FEV}$, returned to $90 \%$ of its initial baseline within 45-60 minutes in all subjects. The $P_{20}$ values for each histamine test are shown in the table. In 17 of the 20 subjects $P_{20}$ test 2 was greater than $P D_{20}$ test 1 . Two subjects did not achieve a $20 \%$ fall in FEV after the highest dose of histamine during the second test.

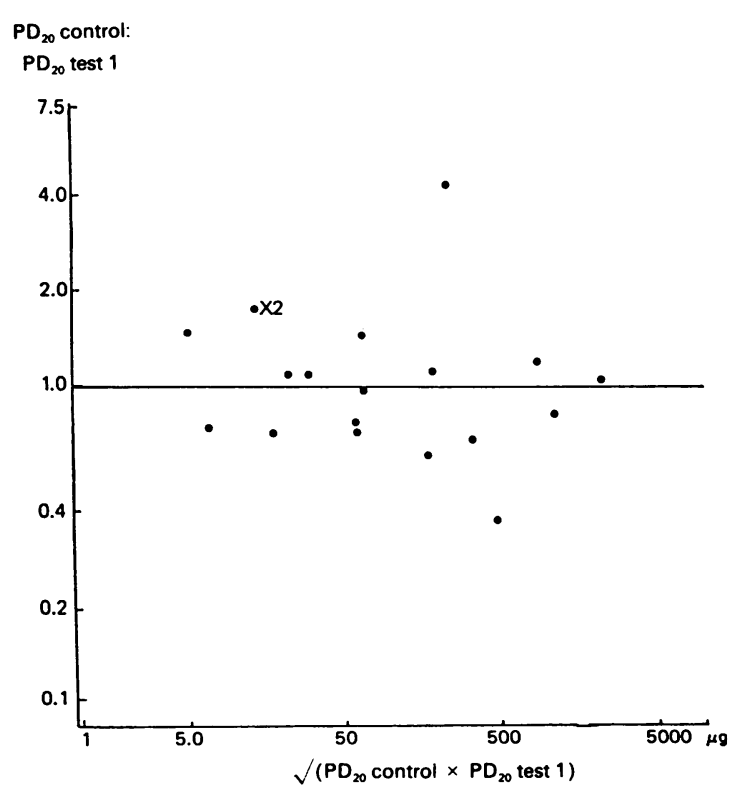

Fig 1 Relation between the ratio $P D_{20}$ control: $P D_{20}$ test 1 and mean $P D_{20}$ (provocative dose of histamine causing a $20 \%$ fall in $F E V_{1}$ ). 
Results of measurements of $P D_{20}$ histamine

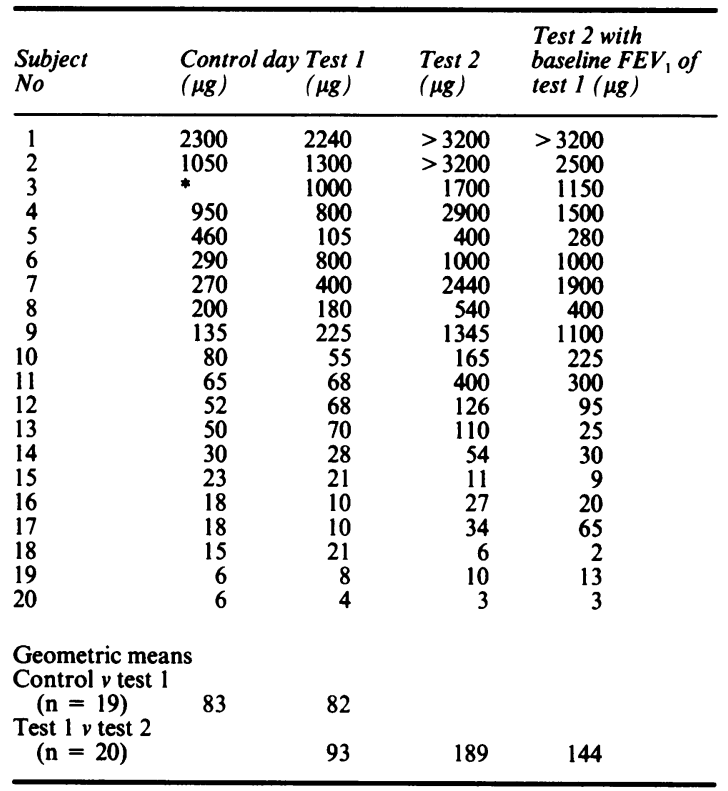

*Subject declined test.

These tests were assigned the maximum $\mathrm{PD}_{20}$ value of $3200 \mu \mathrm{g}$ - a procedure that underestimates any refractory effect. The geometric mean $\mathrm{PD}_{20}$ for test $2(189 \mu \mathrm{g})$ was greater than that for test $1(93 \mu \mathrm{g})$, and the median refractory index of 2.20 was significantly greater than $1(96 \%$ confidence interval $1.43-3 \cdot 40 ; p=0.003)$.

The geometric mean control $\mathrm{PD}_{20}$ measurements (19 subjects only) was $83 \mu \mathrm{g}$, compared with $82 \mu \mathrm{g}$ for the corresponding test 1 measurements. The $\mathrm{PD}_{20}$ control: $\mathrm{PD}_{20}$ test 1 ratio (fig 1 ) was not related to the geometric means of each paired $\mathrm{PD}_{20}$ control and $\mathrm{PD}_{20}$ test 1 (that is, to the best estimate of the true or "usual" $\mathrm{PD}_{20}$ ); nor did the median ratio, 1.03, differ significantly from $1(98 \%$ confidence interval $0.71-$ 1.45).

\section{EFFECT OF BASELINE FEV 1 ON DEGREE OF REFRACTORINESS}

The mean baseline $\mathrm{FEV}_{1}$ was significantly lower for test 2 than that for test $1(3.52 v 3.71$ litres; $\mathrm{p}<0.001)$. This may have affected the second $\mathrm{PD}_{20}$ measurement, as the second challenge was carried out at a time when further recovery in $\mathrm{FEV}_{1}$ might have been expected after the first test. The dose of histamine represented by $P_{20}$ test 2 would in these circumstances have been the dose that antagonised any recovery and in addition provoked a $20 \%$ decrement in $\mathrm{FEV}_{1}$. This would increase the value of $P D_{20}$ test 2 and exaggerate the refractoriness measurement.

The potential strength of this possible artefact was
$\mathrm{PD}_{20}$ test 2:

$P_{20}$ test 1

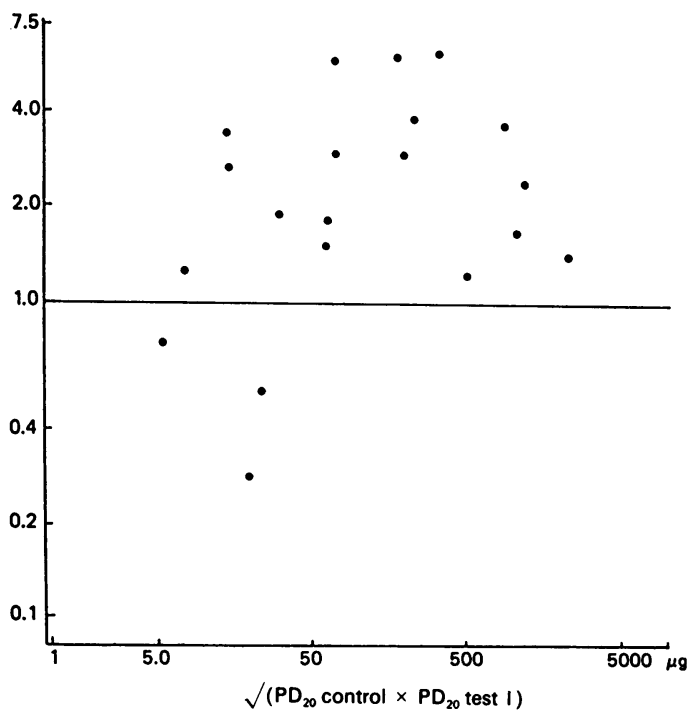

Fig 2 Relation between the ratio $P D_{20}$ test $2: P D_{20}$ test 1 (refractory index) and mean $P D_{20}$ (provocative dose of histamine causing a $20 \%$ fall in $F E V_{l}$ ).

examined by recalculating $\mathrm{PD}_{20}$ test 2 as a $20 \%$ fall from the baseline $F E V_{1}$ of test 1 (table). This assumes that during the course of the second test the FEV would have recovered fully to its original baseline had it not been for the second histamine challenge. This produced an amended geometric mean $\mathrm{PD}_{20}$ for the second test of $144 \mu \mathrm{g}$ and an amended median refractory index of 1.75 , which still differed significantly from $1(96 \%$ confidence interval, 1.15-2.67; $p=0.012)$. The median ratio of the original refractory index $(2 \cdot 20)$ to the amended refractory index $(1 \cdot 75)$ was also significantly different from 1 $(p=0.013)$.

RELATION BETWEEN REFRACTORINESS AND PD 20 The relation between the refractory index $\left(\mathrm{PD}_{20}\right.$ test 2 : $\mathrm{PD}_{20}$ test 1 ) in each subject and the geometric mean $\mathrm{PD}_{20}$ values from the control test and test 1 is shown in figure 2. All 14 subjects with a mean $P_{20}$ above $25 \mu \mathrm{g}$ showed a refractory index greater than 1 . When the amended $P_{20}$ test 2 values were used, the refractory index consistently exceeded 1 when the mean $\mathbf{P D}_{20}$ was above $100 \mu \mathrm{g}$.

\section{Discussion}

This study has found a diminished bronchoconstrictor response to histamine in most of the 20 asthmatic subjects given a second histamine inhalation test 45-60 minutes after an initial test. We therefore support the 
suggestion that histamine provoked bronchoconstriction induces refractoriness, at least in some individuals. A refractory index exceeding 1 was not observed uniformly with high levels of bronchial responsiveness (that is, low $\mathrm{PD}_{20}$ values), however, and our results suggest a possible $\mathrm{PD}_{20}$ threshold of the order of $25-100 \mu \mathrm{g}$ histamine. Above this threshold the refractory index did not appear to be related to $\mathrm{PD}_{20}$, implying that other factors help to determine the degree of refractoriness, once the $\mathrm{PD}_{20}$ (and dose of histamine) are sufficiently high for refractoriness to occur.

The failure of some investigations to show refractoriness is unexplained-unless the subjects in these studies had high levels of airway responsiveness. Adequate numbers of subjects and reasonable precision in the measurement of $\mathbf{P D}_{20}$ are necessary if refractoriness is to be recognised, and baseline levels of ventilatory function should be closely similar for the paired tests. Investigations measuring bronchial responsiveness by means other than the $\mathrm{PD}_{20} \mathrm{FEV}_{1}$ may not produce as much bronchoconstriction (or give as much histamine), and this too could minimise the refractory effect. Finally, it is not always clear that studies failing to detect a refractory period were carried out on typical asthmatic subjects rather than subjects with relatively fixed airway obstruction attributable to cigarette smoking."

The magnitude of the refractory effect generated by a single histamine test was appreciable though not substantial, the median refractory index being $2 \cdot 20$ (range 0.24-6.1). The range observed above the "threshold" of refractoriness was 1-3-6.1. Refractoriness of this degree could exert an important confounding effect when histamine challenge tests are used repeatedly within a single day to measure bronchial responsiveness. For example, bronchial responsiveness to histamine was shown to increase 1 to 2 hours after exposure to respirable industrial agents associated with occupational asthma, before the onset of the ensuing late asthmatic reactions. ${ }^{20}$ Refractoriness here would have diminished the true magnitude of this effect and could have masked it. Investigations showing an apparent circadian rhythm in bronchial responsiveness from frequently repeated histamine tests at uneven intervals may have been subjected to both masking and exaggerating distortions because of the refractory effect. The duration of the refractory period, which Manning et al estimated to be of the order of three to six hours, is obviously a critical factor. ${ }^{9}$ Until this is established, the importance and strength of the refractory effect as a confounding factor will remain unclear.

It is improbable that our observations could have been generated by an artefact in the histamine delivery system. If the nebuliser is used continuously, its output may be expected to decline owing to cooling, but with intermittent use this is unlikely and we have found no evidence of it in practice. A further possible artefact from repeated nebuliser use is increasing concentration of the histamine solution from evaporation. This is unlikely to be important when solutions are replaced daily, as was the practice in this study. In any event, increasing concentration would tend to mask, not exaggerate, refractoriness.

The failure of some subjects to regain their initial baseline level of FEV, before the second histamine test is potentially a more serious flaw. A small degree of residual bronchoconstriction could produce more central deposition of subsequent doses of inhaled histamine, with greater bronchoconstriction because histamine receptors are more concentrated in the central airways. ${ }^{21}$ Geometric factors may also have a role, though these effects are more likely to reduce the second $\mathrm{PD}_{20}$ measurement. ${ }^{22}$ Residual bronchoconstriction provoked by methacholine was found not to influence histamine responsiveness in one study when this was measured on the basis of specific airway conductance. ${ }^{23}$

A major concern is that the $F E V_{1}$ may have continued to increase were it not for the second histamine test. This implies that the $\mathrm{PD}_{20}$ of the second challenge was amplified by the need to antagonise the continuing recovery and cause a $20 \%$ fall in $\mathrm{FEV}_{1}$ in addition. This would increase the $\mathrm{PD}_{20}$ and stimulate or exaggerate a refractory effect. In the present study this effect is unlikely to have exerted a major influence because the $\mathrm{FEV}_{1}$ had returned to at least $90 \%$ of baseline in all patients before the second test was started (mean value $95 \%$ of baseline). We did, however, attempt to quantify the size of this effect by recalculating $\mathrm{PD}_{20}$ values for the second test using the baseline FEV , from the first test. Appreciable refractoriness remained evident even though the decrease in median refractory index from 2.20 to 1.75 was significant. The amended refractory index of 1.75 may represent an overcorrection, however, as it assumes that the baseline FEV , would have been regained fully by every subject during the period of the second test and it ignores the other potential confounders that may have exerted a masking influence on refractoriness.

Our findings are supported by observations that both canine $e^{24}$ and human ${ }^{25}$ airway smooth muscle readily develop refractoriness to repeated stimulation with histamine in vitro. Depletion of mediator stores in mast cells, which has been proposed as the mechanism for exercise induced refactoriness, ${ }^{26}$ is not likely to be relevant to histamine induced refractoriness. The fact that some degree of refractoriness has been found in response to a wide range of directly and indirectly acting bronchoconstrictors suggests that changes in 
the end organ (that is, the airway smooth muscle itself) might be responsible. In the dog this appears to be mediated by a bronchorelaxant prostaglandin, probably $\mathrm{PGE}_{2}{ }^{27}$ The same mechanism may be responsible for histamine tachyphylaxis in human airways, ${ }^{9}$ where indomethacin has been shown to increase the steepness of inhaled histamine dose-response curves. ${ }^{28}$

MJC was supported by the Newcastle Health Authority research commitee.

\section{References}

1 Edmunds T, Tooley M, Godfrey S. The refractory period after exercise-induced asthma: its duration and relation to the severity of exercise. Am Rev Respir Dis 1978;117:247-54.

2 Bar-Yishay E, Ben-Dov I, Godfrey S. Refractory period after hyperventilation induced asthma. Am Rev Respir Dis 1983;127:572-4.

3 Anderson SD, Schoeffel RE, Finney M. Evaluation of ultrasonically nebulised solutions for provocation testing in patients with asthma. Thorax 1983;38:284-91.

4 Kern R, Smith LJ, Patterson R et al. Characterisation of the airway response to inhaled leukotriene D4 in normal subjects. Am Rev Respir Dis 1986;133:1127-31.

5 Cuss FM, Dixon CMS, Barnes PJ. Effect of inhaled platelet activating factor on pulmonary function and bronchial responsiveness in man. Lancet 1986;ii: 189-92.

6 Magnussen H, Reuss G, Jorres R. Theophylline has a dose-related effect on the airway response to inhaled histamine and methacholine in asthmatics. Am Rev Respir Dis 1987;136:1163-7.

7 Beckett WS, McDonnell WF III, Wong ND. Tolerance to methacholine inhalation challenge in non asthmatic subjects. Am Rev Respir Dis 1988;137:1499-501.

8 Schoeffel RE, Anderson SD, Gillam I, Lindsay DA. Multiple exercise and histamine challenge in asthmatic patients. Thorax 1980;35:164-70.

9 Manning PJ, Jones GL, O'Byrne PM. Tachyphylaxis to inhaled histamine in asthmatic subjects. $J$ Appl Physiol 1987;63:1572-7.

10 Manning PJ, O'Byrne PM. Histamine bronchoconstriction reduces airway responsiveness in asthmatic subjects. Am Rev Respir Dis 1988;137:1323-5.

11 Ruffin RE, Alpers JH, Crockett AJ, Hamilton R. Repeated histamine inhalation tests in asthmatic patients. J Allergy Clin Immunol 1981;67:285-9.

12 Hariparsad D, Wilson N, Dixon C, Silverman M. Reproducibility of histamine challenge tests in asthmatic children. Thorax 1983;38:258-60.
13 Hahn AG, Nogrady SG, Tumility DMcA, Lawrence SR, Morton AR. Histamine reactivity during the refractoryos period after exercise-induced asthma. Thoraxo 1984;39:919-23.

14 Gerritsen J, Koeter GH, Akkerboom HJ, Knol K. Recovery of FEV, after histamine challenge in asth- $\overline{\widehat{\sigma}}$ matic children. Clin Allergy 1987;17:119-26.

15 Fabbri LM, Mapp CE, Hendrick DJ. Standardisation of the dosimeter method for measurement of airway $\vec{A}$ responsiveness in man. In: Hargreave FE, Woolcock. AJ, eds Airway responsiveness: measurement and inter $-\vec{\omega}$ pretation. Mississauga: Astra 1985:29-34.

16 Chai H, Farr RS, Froelich LA, et al. Standardisation of bronchial inhalation challenge procedures. J Allergy Clin Immunol 1975;56:323-7.

17 Connolly MJ, Avery AJ, Walters EH, Hendrick DJ. Theî use of sequential doses of inhaled histamine in the $\vec{A}$ measurement of bronchial responsiveness: cumulative $\rightarrow$ effect and distortion produced by shortening the test 은 protocol. J Allergy Clin Immunol 1988;82:863-8.

18 Cockcroft DW, Murdock KY, Mink KT. Determination T of histamine $\mathrm{PD}_{20}$. Comparison of linear and logarith- $\mathrm{O}$ mic interpolation [letter]. Chest 1983;84:505-6.

19 Kendall M, Stuart A. The advanced theory of statistics Vol 2: Inference and relationships. 4th ed. London: Charles Griffen, 1979:537.

20 Durham SR, Graneek BJ, Hawkins R, Newman Taylor. AJ. The temporal relationship between increases in airway responsiveness to histamine and late asthmatic responses induced by occupational agents. J Allergy Clin Immunol 1987;79:398-406.

21 Ruffin RE, Dolovich MB, Wolff RK, Newhouse MT. The effects of preferential deposition of histamine in the 2 human airway. Am Rev Respir Dis 1978;117:485-92. $\overrightarrow{\vec{\beta}}$

22 Benson MK. Bronchial hyperreactivity. Chest $\cong$ 1975;69:227-39.

23 Chung KF, Snashall PD. Effect of prior bronchoconstriction on the airway response to histamine in normal subjects. Thorax 1984;39:40-5.

24 Anderson WH, Krzanowski JJ, Polson JB, Sventivanyi A. Prostaglandins as mediators of tachyphylaxis to ${ }^{x}$ histamine in canine tracheal smooth muscle. Advances in Prostaglandin and Thromboxane Research 1980; 7:995-1001.

25 Hawkins DF, Schild HO. The action of drugs on isolated human bronchial chains. Br J Pharmacol 1951;6:응 682-90. 26 Godfrey S. Exercise-induced asthma. Allergy 1978;33. 을.
$229-37$.

27 Shore S, Martin JG. Tachyphylaxis to inhaled aerosolised ${ }^{N}$ histamine in anaesthetized dogs. J Appl Physiol 1985;59:1355-63.

28 Walters EH. Prostaglandins and the control of airways responses to histamine in normal and asthmatico subjects. Thorax 1983;38:188-94. 